OPEN ACCESS

Edited by:

Arash Mahajerin,

Children's Hospital of Orange County,

United States

Reviewed by:

Lindsey A. George,

Children's Hospital of Philadelphia,

United States

Wenndy Hernandez,

University of Chicago,

United States

*Correspondence:

Cristina Tarango

cristina.tarango@cchmc.org

Specialty section:

This article was submitted to

Pediatric Hematology and

Hematological Malignancies,

a section of the journal

Frontiers in Pediatrics

Received: 31 January 2017 Accepted: 20 November 2017

Published: 06 December 2017

Citation:

Tarango C and Manco-Johnson MJ (2017) Pediatric Thrombolysis: A Practical Approach.

Front. Pediatr. 5:260.

doi: 10.3389/fped.2017.00260

\section{Pediatric Thrombolysis: A Practical Approach}

\author{
Cristina Tarango ${ }^{1 *}$ and Marilyn J. Manco-Johnson ${ }^{2}$ \\ ${ }^{1}$ Division of Hematology, Department of Pediatrics, Cancer and Blood Diseases Institute, Cincinnati Children's Hospital \\ Medical Center Cincinnati, University of Cincinnati, Cincinnati, OH, United States, ${ }^{2}$ Department of Pediatrics, Section of \\ Hematology, Oncology, and Bone Marrow Transplantation, University of Colorado Anschutz Medical Campus, Children's \\ Hospital, Aurora, CO, United States
}

The incidence of pediatric venous thromboembolic disease is increasing in hospitalized children. While the mainstay of treatment of pediatric thrombosis is anticoagulation, reports on the use of systemic thrombolysis, endovascular thrombolysis, and mechanical thrombectomy have steadily been increasing in this population. Thrombolysis is indicated in the setting of life- or limb-threatening thrombosis. Thrombolysis can rapidly improve venous patency thereby quickly ameliorating acute signs and symptoms of thrombosis and may improve long-term outcomes such as postthrombotic syndrome. Systemic and endovascular thrombolysis can result in an increase in minor bleeding in pediatric patients, compared with anticoagulation alone, and major bleeding events are a continued concern. Also, endovascular treatment is invasive and requires technical expertise by interventional radiology or vascular surgery, and such expertise may be lacking at many pediatric centers. The goal of this mini-review is to summarize the current state of knowledge of thrombolysis/thrombectomy techniques, benefits, and challenges in pediatric thrombosis.

\footnotetext{
Keywords: pediatric thrombosis, pediatric thrombolysis, DVT therapy, pediatric DVT, thrombolysis, combination therapy
}

\section{INTRODUCTION}

The incidence of pediatric venous thromboembolism (VTE) is estimated to be $0.07-0.14 / 10,000$ children $(1,2)$, and data suggest that the incidence of thrombosis in children is dramatically increasing (3). This increase may be due in part to the advancement in the management and invasive supportive care of critically ill children and improved imaging modalities to diagnose VTE. Several risk factors for pediatric thrombosis have been identified, including the presence of a central venous catheter (CVC), cancer, congenital heart disease, and surgery (4).

The mainstay of therapy of acute pediatric thrombosis is anticoagulation, and the goals of anticoagulation are to prevent propagation of acute thrombosis, prevent recurrence, and prevent embolization. The most commonly used anticoagulants are unfractionated heparin (UFH), lowmolecular-weight heparins (LMWH), and vitamin K antagonists (5). Unfortunately, anticoagulation alone does not rapidly restore the patency of occluded vessels, and in patients at high risk for acute venous insufficiency, VTE recurrence, or postthrombotic syndrome (PTS), anticoagulation may not be enough to achieve optimal outcomes. Moreover, the additional risk factors for and the frequency of adverse outcomes in pediatric thrombosis remain poorly understood. Recurrent thrombosis can occur in $7-8 \%$ of children $(2,4)$. It is estimated that nearly $2 \%$ of pediatric venous thrombosis 
will directly result in death (4), with 4-9\% mortality in arterial thrombosis (6). Long-term complications can include limblength discrepancies and claudication with arterial thrombosis (7), and PTS with venous thrombosis. PTS is the most common chronic complication of VTE and can manifest as pain, edema, and venous stasis ulcers; PTS can limit age-appropriate activities, resulting in a significant impact on children's quality of life (8). PTS is seen in about $26 \%$ of children with extremity venous thrombosis (9).

Thrombolysis has been used in pediatrics for decades (10-15), but in the last 10-20 years, its use has gained momentum with the improved capability of laboratory monitoring, radiologic imaging, interventional radiology, and surgical interventions. In pediatrics, one can consider two broad groups of patients that account for most thrombolysis therapy for VTE. The first group of candidates for thrombolysis may be children and adolescents who present with community(home)-acquired VTE. The second group consists of children with complex congenital heart disease or chronic conditions who develop venous insufficiency related to abnormal hemodynamics, surgical interventions, and lifedependence on CVCs $(16,17)$. Yet, without high-quality clinical trials of thrombolysis in pediatric thrombosis, providers are left without clear indications for the use of thrombolysis and without uniform dosing regimens. Most importantly, we have limited data on the risks and outcomes of thrombolysis. With this in mind, we will review current data on thrombolysis and offer guidance on its use in pediatric thrombosis outside of the central nervous system.

\section{BACKGROUND}

\section{Fibrinolytic System}

The fibrinolytic system is a dynamic system that continues to develop following birth (14), and is regulated by various cofactors and inhibitors (18). During fibrinolysis, the zymogen plasminogen is activated by two main serine proteases, tissue-type plasminogen activator (tPA) and urokinase-type plasminogen activator (uPA). tPA binds to fibrin at lysine binding sites and converts plasminogen into plasmin. uPA has no fibrin specificity and can activate both fibrin-bound and circulating plasminogen (14). Both activators have a short half-life of 4-8 min due to the actions of circulating inhibitors: plasminogen activator inhibitor (PAI-1), thrombin-activatable fibrinolysis inhibitor (TAFI), and alpha-2 antiplasmin, which inactivate plasmin or impair plasmin formation (18).

Neonates and infants have qualitative and quantitative differences in plasminogen compared with older children and adults (19). Plasminogen levels increases to adult levels by 6 months of age (20). TPA is also decreased at birth while PAI-1 levels are normal or increased; levels of tPA and PAI-1 do not reach adult levels until late adolescence. Thus, fibrinolysis throughout childhood may be downregulated. Low levels of plasminogen have been shown to impact the actions of pharmacologic thrombolytics (21), but there are insufficient data to demonstrate what effect, if any, high levels of PAI-1 or other fibrinolysis inhibitors may have on the activity of thrombolytic therapy throughout childhood.

\section{PHARMACOLOGIC AGENTS}

In contrast to anticoagulants that decrease the body's ability to form new thrombus, thrombolytic agents act by converting plasminogen to plasmin and thereby actively reduce clot burden. Several thrombolytics have been used in pediatrics: streptokinase, urokinase, and recombinant tPA (rtPA). In an in vitro model of thrombolysis using the three agents, streptokinase showed the slowest rate for clot lysis, tPA had improved lysis early on, and urokinase showed better fibrinolytic specificity (22). Recombinant tPA has a high affinity for fibrin, and the fibrin-tPA complex enhances the binding of plasminogen to fibrin, localizing the effects to the site of thrombosis. rtPA is recommended in pediatrics over other thrombolytics (23), and our review will focus on rtPA.

Recombinant tPA was first FDA approved in the 1980s (24) and initially was used in adults for coronary artery thrombolysis and has since been widely used for stroke (25) and unstable pulmonary embolism (26). The earliest reports in pediatrics were the use of systemic rtPA for catheter-associated arterial thrombosis $(11,13)$ and pulmonary embolism (12). There are several formulations of rtPA: alteplase with a half-life of 3-5 min, and two modified rtPAs: reteplase ${ }^{\circledR}$ with a half-life of 13-16 min, and tenecteplase with a half-life of 20-24 min. Alteplase is most commonly used in pediatrics due to its short half-life, and dosing for thrombolysis in children is not standardized.

\section{GENERAL CONSIDERATIONS}

\section{Recommended Resources}

To improve the safety of and optimize outcomes in patients receiving thrombolysis, a multidisciplinary approach is needed (27). The ability to quickly obtain coagulation testing results for ongoing adjustments in therapy is critical for managing patients receiving thrombolysis and concomitant anticoagulation. Thrombolysis should occur in the critical care setting to allow for rapid intervention should bleeding occur. Access to imaging modalities such as duplex ultrasound, computed tomography, and magnetic resonance imaging also allows for the necessary surveillance of thrombolysis. For endovascular thrombolysis, experienced interventional radiologists or interventional cardiologists familiar with techniques in young patients must be available.

\section{Laboratory Monitoring}

Whether systemic or endovascular thrombolysis is used, concomitant use of anticoagulation is recommended to prevent new thrombus formation during thrombolysis, as clot lysis releases active thrombin which was bound to thrombi (28). Reported dosing of concomitant anticoagulation has ranged from therapeutic UFH to UFH at a set dose of 5-10 units/kg/h (29-31). While UFH therapy alone can be monitored using either aPTT or anti-Xa levels, anti-Xa levels should be monitored during thrombolysis when possible. Fibrin split products can prolong the activated thromboplastin time (aPTT), thus aiming for a specific aPTT is of unclear utility during thrombolysis. Infants or any child with suspected acquired plasminogen deficiency should receive fresh frozen plasma prior to initiation of thrombolysis. 
Careful laboratory monitoring during thrombolysis is required, with hemoglobin/hematocrit, platelet count, fibrinogen, fibrin degradation products, D-dimer, aPTT, prothrombin time, and UFH anti-Xa levels done every 6-12 h. D-Dimer levels can help direct systemic thrombolysis therapy, as a normal or low D-dimer indicates a lack of thrombolysis and can be used to guide dose increases, while an elevated $\mathrm{D}$-dimer indicates that chemical activation of fibrinolysis has been achieved. A current blood type and screen is also recommended for any patient receiving thrombolysis, as is a renal panel for patients requiring contrast for venography or undergoing mechanical thrombolysis, due to a risk of hemolysis with the latter.

\section{Timing of Thrombolysis}

In general, thrombolysis is used in acute thrombosis of less than 14 days duration of vessel occlusion. In one study assessing efficacy of systemic thrombolysis, $83 \%$ of patients with thrombus less than 2 weeks had full or partial response to rtPA compared with $25 \%$ in those patients where the thrombus was older (32). For endovascular pharmacomechanical thrombolysis, though, some investigators suggest that more than 60 days from the onset of symptoms is a contraindication (33), although recent attempts to revascularize chronic venous occlusions are proving promising and can be considered for high-risk thrombi $(34,35)$.

\section{Precautions and Contraindications}

Several precautions should be taken during thrombolysis:

A. No arterial punctures or line placements.

B. No intramuscular injections.

C. Minimal manipulation of the patient (e.g., no chest physiotherapy).

D. No urinary catheterization, rectal temperatures, nasogastric tube placement.

E. Blood samples should be obtained from a superficial vein or indwelling catheter.

F. Avoid concurrent NSAIDs or anti-platelet therapy.

G. Intracranial imaging should be considered prior to and after thrombolytic therapy in children less than 3 months of age or any child at high risk for ischemic or hemorrhagic stroke.

While the decision to use thrombolysis should be made on a case-by-case basis, weighing pertinent risks, and benefits, there are general contraindications to thrombolysis that should be considered $(27,36)$.

A. Active bleeding.

B. Concurrent bleeding diathesis: inability to maintain platelets greater than $100,000 / \mu \mathrm{l}$ and fibrinogen above $100 \mathrm{mg} / \mathrm{dL}$ using transfusion support.

C. Recent major surgery or trauma, puncture of a noncompressible vessel, or organ biopsy within the previous 10 days.

D. Intracranial hemorrhage, infarction or intracranial or spinal surgery within the last 2 months.

E. Known right-to-left intracardiac shunt.

F. Cardiopulmonary resuscitation or asphyxia within 7 days of therapy (including complicated birth).

G. Extreme prematurity.
Other contraindications to thrombolysis have included pregnancy or puerperium; presence of intracranial vascular malformations, aneurysms or neoplasms; uncontrolled hypertension; infective endocarditis; and any contraindication to the use of unfractionated heparin or radiographic contrast media (if needed for assessment of thrombosis) (27).

\section{INDICATIONS AND PATIENT SELECTION}

Acute or subacute occlusive venous or arterial thrombosis that is limb- or life-threatening is the primary indication for thrombolysis. Thrombolysis can improve limb and organ perfusion by improving vessel patency and may quickly improve symptoms. Consensus guidelines offer indications for thrombolysis (23), but its use must be carefully considered due to the potential higher risk of major bleeding compared with anticoagulation alone.

\section{Strong Indications for Thrombolysis}

A. Arterial thrombosis with tissue ischemia.

B. Phlegmasia alba/cerulea dolens: extensive venous thrombosis with total occlusion of venous flow, increased compartment pressures and compromise of arterial blood flow (37).

C. Pulmonary embolism (PE) with hypotension or shock, or PE resulting in right heart strain or myocardial necrosis.

D. Superior vena cava syndrome.

E. Bilateral renal vein thrombosis.

F. Congenital heart disease with shunt thrombosis.

G. Large $(>2 \mathrm{~cm})$, mobile right atrial thrombus.

H. Kawasaki disease with coronary artery thrombosis.

I. Cerebral sinovenous thrombosis with neurologic impairment and no improvement with anticoagulation or progressive thrombosis.

\section{Possible Indications for Thrombolysis}

In the past decade, there have been reports of the use of thrombolysis in children for indications beyond acute limb- or life-threatening situations $(31,33,38,39)$. The goal of therapy in these cases is often to improve long-term outcomes or to maintain venous patency in children dependent on central venous access (17). Small prospective and retrospective case series suggest that the use of thrombolysis may be indicated for occlusive, symptomatic iliofemoral or inferior vena cava DVT to acutely decrease pain and improve function and, long-term, to potentially decrease the risk of (PTS) $(31,33,38)$. Thrombolysis has been shown to decrease PTS in adults (40). Venous compression syndromes such as May-Thurner $(41,42)$ and Paget Schroetter (43) (effort thrombosis) have also been treated with combined thrombolysis and endovascular or surgical techniques. Table 1 shows the results of published case series or cohort studies and demonstrates convergent results in thrombolysis efficacy, and rates of recurrence, PTS, and major bleeding.

\section{METHODS OF THROMBOLYSIS}

The choice of either systemic or endovascular thrombolysis depends on several factors. Foremost, is the availability of interventional radiologists/cardiologists who have pediatric expertise 
with delivering site-directed endovascular treatment. There are sparse data on endovascular thrombolysis in certain anatomic areas such as the pulmonary vasculature (45), or cerebral venous sinuses (46), so systemic thrombolysis, rather than endovascular, is recommended for these sites. Another factor that may impact the mode of thrombolysis is the acuity of impending loss of life or limb, as the time to coordinate endovascular thrombolysis may be prohibitive. Also, a patient at higher risk of bleeding may benefit from endovascular thrombolysis as some data suggests that endovascular thrombolysis has a lower risk of bleeding than systemic thrombolysis (47).

\section{Systemic Thrombolysis}

Systemic thrombolysis is the intravenous administration of thrombolytics distant from the site of thrombosis. Case series using rtPA in children have used various dosing regimens with differing rates of success $(29,48,49)$. A low-dose rtPA infusion and a high-dose (previously referred to as "standard dose") rtPA regimen have been described, with low-dose therapy showing equivalent efficacy to a high-dose regimens $(29,30)$. High-dose
rtPA can be used for $6 \mathrm{~h}$ at a time and may be repeated over a $72-\mathrm{h}$ period if imaging suggests no response. Low-dose rtPA can be a continuous infusion over 6-72 h, with close laboratory monitoring and imaging at a minimum of daily. Table 2 describes dosing regimens.

In a review of pediatric thrombolysis, the reported overall number of patients with complete or partial resolution of thrombosis with systemic thrombolysis was $79 \%$, with an incidence of major bleeding in 15\% (47). Major bleeding is most often defined as fatal bleeding, bleeding resulting in a drop in hemoglobin of $2 \mathrm{~g} / \mathrm{dL}$ or more within $24 \mathrm{~h}$, retroperitoneal, pulmonary or intracranial, and bleeding requiring surgical intervention (50). Major bleeding events in children receiving systemic thrombolysis are often associated with longer tPA infusion times and a lower fibrinogen level immediately after thrombolysis (48).

\section{Endovascular Thrombolysis}

No studies have compared endovascular to systemic thrombolysis in children. Advantages of directed therapy are lower doses of rtPA, with potentially less risk of bleeding, and the ability to

TABLE 1 | Published results of thrombolysis in children.

\begin{tabular}{|c|c|c|c|c|c|c|c|c|}
\hline Author & Method & $N$ & $\begin{array}{l}\text { Age, range and site of } \\
\text { thrombosis }\end{array}$ & Lysis $^{a}$ & $\begin{array}{l}\text { Major } \\
\text { hemorrhage }\end{array}$ & SAEs, other & $\begin{array}{l}\text { Recurrent } \\
\text { VTE }\end{array}$ & PTS \\
\hline Manco-Johnson (28) & $\begin{array}{l}\text { Systemic } \\
\text { UK/UH }\end{array}$ & 32 & $\begin{array}{l}6 \text { weeks to } 17 \text { years and UE, LE, } \\
\text { SVC, IVC, PE, atrial }\end{array}$ & $50 \%$ & 0 & $\begin{array}{l}\text { Death 1; PE 1; } \\
\text { progress } 1\end{array}$ & $9 \%$ & $11.1 \% \mathrm{MJ}$ \\
\hline Wang (29) & Systemic TPA & $\begin{array}{l}12 \mathrm{HD} \\
17 \mathrm{LD}\end{array}$ & $\begin{array}{l}1 \text { day to } 17 \text { years and LE, UE, } \\
\mathrm{PE}, \mathrm{CSVT} \text {, renal, hepatic, arterial, } \\
\text { and venous }\end{array}$ & $\begin{array}{c}92 \% \\
100 \%\end{array}$ & $\begin{array}{l}0 \\
1 \mathrm{ICH}, \mathrm{PT} \text { infant }\end{array}$ & $\begin{array}{l}1 \text { embolic stroke } \\
\text { with left atrial } \\
\text { thrombus }\end{array}$ & 0 & $\begin{array}{l}8 \% \\
0 \% \\
\mathrm{MJ}\end{array}$ \\
\hline Goldenberg (38) & Systemic/PPMT & 9 & 1-21 years and LE & $89 \%$ & 1 pulmonary & 0 & $0 \%$ & $\begin{array}{c}11.1 \% \\
\text { MJ }\end{array}$ \\
\hline Goldenberg (33) & CDT/PMT/PPMT & 16 & 11-19 years and LE and UE & $88 \%$ & 0 & PE 1 & $27 \%$ & $\begin{array}{l}13 \% \\
\mathrm{MJ}\end{array}$ \\
\hline Darbari (39) & CDT/PMT/PPMT & 34 & $\begin{array}{l}13 \text { days to } 21 \text { years and LE } \\
\text { and UE }\end{array}$ & $\begin{array}{l}17 \%(52 \%) \\
50(99 \%)\end{array}$ & $\begin{array}{l}1 \\
2 \text { required prbcs }\end{array}$ & $0 \%$ & NA & NA \\
\hline Dandoy (31) & CDT/PMT/PPMT & 41 & $\begin{array}{l}3 \text { months to } 21 \text { years and LE, } \\
\text { UE, SVC, and IVC }\end{array}$ & $90 \%(>50 \%)$ & $\begin{array}{l}1 \\
\text { Required prbcs }\end{array}$ & PE 1 & NA & $\begin{array}{c}14 \%(\mathrm{~V} \text { or } \\
\mathrm{mV})\end{array}$ \\
\hline Gaballah (55) & CDT/PMT/PPMT & 57 & $1-17$ years and LE & $\begin{array}{l}33 \%(93.7 \%) \\
\quad>50 \%\end{array}$ & $1.8 \%$ & & $12 \%$ & $\begin{array}{c}2.1 \% \mathrm{~V} \\
59.3 \% \mathrm{mV}\end{array}$ \\
\hline
\end{tabular}

a Lysis indicates 90-100\% clot lysis; studies reports indicating 50-99\% lysis or >50-\% lysis are so noted.

$N$, number of cases; SAE, serious adverse events; VTE, venous thromboemobolism; PTS, postthrombotic syndrome; UK, urokinase; UH, unfractionated heparin; TPA, tissue plasminogen activator; ICH, intracranial hemorrhage; PT, preterm; PE, pulmonary embolism; MJ, Manco-Johnson PTS scale; PPMT, percutaneous pharmacomechanical thrombolysis; CDT, catheter-directed thrombolysis; PMT, percutaneous mechanical thrombolysis; prcs, packed red cells; NA, not available; V, Villalta PTS scale; mV, modified Villalta PTS scale. LE, lower extremity; UE, upper extremity; SVC, superior vena cava; IVC inferior vena cava.

TABLE 2 | Dosing of alteplase and heparin during thrombolysis.

\begin{tabular}{|c|c|c|c|c|c|}
\hline \multirow{2}{*}{$\begin{array}{l}\text { Mode of } \\
\text { thrombolysis }\end{array}$} & \multicolumn{2}{|c|}{ Alteplase dosing } & \multirow{2}{*}{$\begin{array}{l}\text { Duration of } \\
\text { thrombolysis }\end{array}$} & \multirow[t]{2}{*}{ Concomitant UFH therapy } & \multirow[t]{2}{*}{ Laboratory monitoring } \\
\hline & Bolus & Infusion & & & \\
\hline $\begin{array}{l}\text { Systemic } \\
\text { thrombolysis }\end{array}$ & $\begin{array}{l}\text { None } \\
\text { None }\end{array}$ & $\begin{array}{l}\text { Low-dose: } 0.01-0.06 \mathrm{mg} / \mathrm{kg} / \mathrm{h} \\
\text { (max } 2 \mathrm{mg} / \mathrm{h}) \\
\text { High-dose: } 0.1-0.5\end{array}$ & $\begin{array}{l}6-72 \mathrm{~h} \\
2-6 \mathrm{~h} \text {, may repeat } \\
\text { if indicated }\end{array}$ & $\begin{array}{l}\text { Prophylactic UFH with goal UFH } \\
\text { anti-Xa level of } 0.1-0.3 \text { or UFH at } \\
10 \mathrm{U} / \mathrm{kg} / \mathrm{h}\end{array}$ & $\begin{array}{l}\text { Every } 6-12 \text { h: fibrinogen, CBC, } \\
\text { FDPs, PT, aPTT, UFH anti-Xa }\end{array}$ \\
\hline $\begin{array}{l}\text { Site-directed } \\
\text { thrombolysis }\end{array}$ & $\begin{array}{l}0.1-0.3 \mathrm{mg} / \mathrm{kg} \\
(\mathrm{max} \text { dose } 10 \mathrm{mg})\end{array}$ & $\begin{array}{l}0.01-0.03 \mathrm{mg} / \mathrm{kg} / \mathrm{h} \text { or } \max \\
1-2 \mathrm{mg} / \mathrm{h}\end{array}$ & Up to $72-96 \mathrm{~h}$ & $\begin{array}{l}\text { Therapeutic UFH with goal UFH } \\
\text { anti-Xa level of } 0.3-0.7 \text { or ufh at } \\
10 \mathrm{U} / \mathrm{kg} / \mathrm{h}\end{array}$ & $\begin{array}{l}\text { Every } 6-12 \text { h: fibrinogen, CBC, } \\
\text { FDPs, PT, aPTT, UFH anti-Xa, } \\
\text { renal profile, urinalysis }\end{array}$ \\
\hline
\end{tabular}


instill the thrombolytic agent directly into or near the thrombus. Endovascular thrombolysis is invasive, and is more costly than systemic thrombolysis due to the need for pediatric intensive care for up to 4 days, requirement of general anesthesia, use of interventional radiology expertise and suite for up to three sessions. In a systematic review of pediatric thrombosis, endovascular thrombolysis resulted in complete resolution in $76 \%$, partial resolution in $17 \%$, and no resolution in $7 \%$ of cases (47). Endovascular thrombolysis can be done over $12-96 \mathrm{~h}$ and can include several interventions (51):

A. Infusion-only, catheter-directed thrombolysis (CDT): This is the placement of a catheter under radiologic imaging directly into the thrombus to deliver thrombolytic agent.

B. Percutaneous mechanical thrombolysis/thrombectomy (PMT): This is the use of intravascular aspirating-type devices without thrombolytic to mechanically remove thrombus. This form of thrombolysis is discouraged because of the possibility of vascular injury and is used when thrombolytics are contraindicated.

C. Percutaneous pharmacomechanical thrombolysis (PPMT): This is the combined use of CDT with a device that mechanically breaks up the thrombus. A commonly used device in children is the Angiojet ${ }^{\mathrm{TM}}$, which uses high-velocity saline jets to generate strong negative pressures to break up and suction out the thrombus. The availability of Angiojet $4 \mathrm{Fr}$ devices allows for use in small vessels. The Ekos ${ }^{\mathrm{TM}}$ system uses ultrasound to instill tPA into the clot and is also gaining acceptance. These devices may cause significant hemolysis (52); intravenous hydration and monitoring of serial creatinine/ renal function and electrolytes is recommended.

There is no standard protocol or preferred device in pediatrics, and use of any of these modalities is often physician-dependent. By allowing direct access to the occluded vessel, endovascular therapy can allow for additional techniques such as angioplasty and stent placement to improve vessel patency. Retrievable IVC filters may be placed at the time of endovascular thrombolysis to prevent embolization (53) but are not always necessary and are placed at the discretion of the interventionalist. If placed, IVC filters can be removed at the end of the procedure or within 3 months of placement. Pulmonary embolism is a known complication of endovascular thrombolysis and has been reported in $1-3 \%(44,54)$. Major bleeding in children undergoing endovascular thrombolysis has been reported to be $0-3 \%(31,33$, 39, 55). Surgical thrombectomy has been reported in severe pediatric thrombosis where anticoagulation and thrombolysis have failed (56), cardiac ventricular thrombosis (57), and IVC thrombosis associated with abdominal tumors (58). Surgical thrombectomy should be reserved for the direst cases.

\section{REFERENCES}

1. Andrew M, David M, Adams M, Ali K, Anderson R, Barnard D, et al. Venous thromboembolic complications (VTE) in children: first analyses of the Canadian Registry of VTE. Blood (1994) 83(5):1251-7.

\section{MANAGEMENT OF BLEEDING COMPLICATIONS}

Bleeding is the most feared complication of thrombolytic therapy. Transfusion of cryoprecipitate should be given for hypofibrinogenemia $(<100 \mathrm{mg} / \mathrm{dL})$ and the platelet count should be maintained above $100 \mathrm{~K} / \mu \mathrm{L}$ during thrombolysis. Menstruating females may receive non-estrogen-containing hormonal suppression with norethindrone before or during thrombolysis. Minor bleeding, such as bleeding from intravenous lines or catheterization site, can be managed with local control (pressure bandages or topical hemostatic agents, e.g., topical thrombin.) If more extensive bleeding occurs, the rtPA infusion can be decreased or temporarily stopped for at least $1 \mathrm{~h}$. Anticoagulation can also be held or the dose lowered if bleeding persists. When bleeding is controlled, the anticoagulation can then be started at lower dose if previously stopped, and the rTPA infusion can be restarted at a lower dose. For major bleeding, such as intracranial or intra-abdominal bleeding, anticoagulation and rtPA should be stopped and cryoprecipitate should be administered. UFH can be reversed with protamine $(1 \mathrm{mg}$ of protamine for $100 \mathrm{U}$ of heparin, maximum protamine dose is $50 \mathrm{mg} / \mathrm{dose}$ ), and an antifibrinolytic such as aminocaproic acid or tranexamic acid be administered (23), although antifibrinolytics are not standard in this setting. Emergent surgical intervention may be required for major bleeding.

\section{SUMMARY AND CONCLUSION}

As the incidence of thrombosis in children increases, providers must be aware of treatment options to optimize outcomes. PTS occurs in nearly $30 \%$ of pediatric patients with thrombosis, which can cause life-long signs and symptoms of limb swelling, pain, and limitations in normal activities. Adult studies suggest that that thrombolysis decreases the risk of PTS by a third (59), and data in pediatrics also suggest that thrombolysis can significantly decrease the incidence of this complication (38). As children are expected to live for decades after a DVT, providers should strongly consider treatment modalities that may decrease the risk of this chronic complication. Thrombolysis can be safely performed in children but requires extensive monitoring and collaboration with hematology, critical care, and in cases of endovascular therapy, interventional radiology or interventional cardiology. Until randomized trials are performed to assess the benefits, risks, and complications of thrombolytic therapy in children, clinicians will need to continue careful patient selection and establish shortand long-term monitoring of patients treated with this therapy.

\section{AUTHOR CONTRIBUTIONS}

CT wrote the manuscript. MM-J reviewed the manuscript.

2. Van Ommen CH, Heijboer H, Büller HR, Hirasing RA, Heijmans HSA, Peters M Venous thromboembolism in childhood: a prospective two-year registry in The Netherlands. J Pediatr (2001) 139(5):676-81. doi:10.1067/mpd.2001.118192

3. Raffini L, Huang Y-S, Witmer C, Feudtner C. Dramatic increase in venous thromboembolism in children's hospitals in the United States 
from 2001 to 2007. Pediatrics (2009) 124(4):1001-8. doi:10.1542/ peds.2009-0768

4. Monagle P, Adams M, Mahoney M, Ali K, Barnard D, Bernstein M, et al. Outcome of pediatric thromboembolic disease: a report from the Canadian Childhood Thrombophilia Registry. Pediatr Res (2000) 47(6):763-6. doi:10.1203/00006450-200006000-00013

5. Law C, Raffini L. A guide to the use of anticoagulant drugs in children. Pediatr Drugs (2015) 17(2):105-14. doi:10.1007/s40272-015-0120-x

6. Monagle P, Newall F, Barnes C, Savoia H, Campbell J, Wallace T, et al. Arterial thromboembolic disease: a single-centre case series study. J Paediatr Child Health (2008) 44(1-2):28-32. doi:10.1111/j.1440-1754.2007.01149.x

7. Price VE, Chan AKC. Arterial thrombosis in children. Expert Rev Cardiovasc Ther (2008) 6(3):419-28. doi:10.1586/14779072.6.3.419

8. Kumar R, Rodriguez V, Matsumoto JMS, Khan SP, Weaver AL, McBane RD, et al. Health-related quality of life in children and young adults with post-thrombotic syndrome: results from a cross-sectional study. Pediatr Blood Cancer (2013) 61(3):546-51. doi:10.1002/pbc.24840

9. Goldenberg NA, Donadini MP, Kahn SR, Crowther M, Kenet G, Nowak-Gottl U, et al. Post-thrombotic syndrome in children: a systematic review of frequency of occurrence, validity of outcome measures, and prognostic factors. Haematologica (2010) 95(11):1952-9. doi:10.3324/haematol.2010.026989

10. Ino T, Benson LN, Freedom RM, Barker GA, Aipursky A, Rowe RD. Thrombolytic therapy for femoral artery thrombosis after pediatric cardiac catheterization. Am Heart J (1988) 115(3):633-9. doi:10.1016/0002-8703(88)90815-0

11. Kennedy LA, Drummond WH, Knight ME, Millsaps MM, Williams JL. Successful treatment of neonatal aortic thrombosis with tissue plasminogen activator. J Pediatr (1990) 116(5):798-801. doi:10.1016/S0022-3476(05)82675-7

12. Pyles LA, Pierpont ME, Steiner ME, Hesslein PS, Smith CM. Fibrinolysis by tissue plasminogen activator in a child with pulmonary embolism. J Pediatr (1990) 116(5):801-4. doi:10.1016/S0022-3476(05)82676-9

13. Levy M, Benson LN, Burrows PE, Bentur Y, Strong DK, Smith J, et al. Tissue plasminogen activator for the treatment of thromboembolism in infants and children. J Pediatr (1991) 118(3):467-72. doi:10.1016/S0022-3476(05)82170-5

14. Andrew M. Anticoagulation and thrombolysis in children. Tex Heart Ins $J$ (1992) 19(3):168-77.

15. Leaker M, Massicotte MP, Brooker LA, Andrew M. Thrombolytic therapy in pediatric patients: a comprehensive review of the literature. Thromb Haemost (1996) 76(2):132-4.

16. Kukreja KU, Lungren MP, Patel MN, Johnson ND, Racadio JM, Dandoy C, et al. Endovascular venous thrombolysis in children younger than 24 months. J Vasc Interv Radiol (2014) 25(8):1158-64. doi:10.1016/j.jvir.2014.04.003

17. Lungren MP, Ward TJ, Patel MN, Racadio JM, Kukreja K. Endovascular thrombolysis to salvage central venous access in children with catheterassociated upper extremity deep vein thrombosis: technique and initial results. J Thromb Thrombolysis (2015) 40(3):274-9. doi:10.1007/s11239-015-1209-3

18. Chapin JC, Hajjar KA. Fibrinolysis and the control of blood coagulation. Blood $\operatorname{Rev}(2015)$ 29(1):17-24. doi:10.1016/j.blre.2014.09.003

19. Parmar N, Mitchell LG, Berry LR, Andrew M, Chan AKC. The influence of age on in vitro plasmin generation in the presence of fibrin monomer. Acta Haematol (2006) 115(3-4):141-51. doi:10.1159/000090927

20. Andrew M, Paes B, Milner R, Johnston M, Mitchell L, Tollefsen DM, et al. Development of the human coagulation system in the full-term infant. Blood (1987) 70(1):165-72.

21. Andrew M, Brooker L, Leaker M, Paes B, Weitz J. Fibrin clot lysis by thrombolytic agents is impaired in newborns due to a low plasminogen concentration. Thromb Haemost (1992) 68(3):325-30.

22. Ouriel K, Welch EL, Shortell CK, Geary K, Fiore WM, Cimino C. Comparison of streptokinase, urokinase, and recombinant tissue plasminogen activator in an in vitro model of venous thrombolysis. J Vasc Surg (1995) 22(5):593-7. doi:10.1016/S0741-5214(95)70045-5

23. Monagle P, Chan AKC, Goldenberg NA, Ichord RN, Journeycake JM, Nowak-Gottl U, et al. Antithrombotic therapy in neonates and children: antithrombotic therapy and prevention of thrombosis, 9th ed: American College of Chest Physicians Evidence-Based Clinical Practice Guidelines. Chest (2012) 141:737S-801S. doi:10.1378/chest.11-2308

24. Collen D, Lijnen HR. The tissue-type plasminogen activator story. Arterioscler Thromb Vasc Biol (2009) 29(8):1151-5. doi:10.1161/ATVBAHA.108.179655

25. Adams HP, del Zoppo G, Alberts MJ, Bhatt DL, Brass L, Furlan A, et al. Guidelines for the early management of adults with ischemic stroke: a guideline from the American Heart Association/American Stroke Association Stroke Council, Clinical Cardiology Council, Cardiovascular Radiology and Intervention Council, and the Atherosclerotic Peripheral Vascular Disease and Quality of Care Outcomes in Research Interdisciplinary Working Groups: The American Academy of Neurology affirms the value of this guideline as an educational tool for neurologists. Stroke (2007) 38(5):1655-711. doi:10.1161/ STROKEAHA.107.181486

26. Wang T-F, Squizzato A, Dentali F, Ageno W. The role of thrombolytic therapy in pulmonary embolism. Blood (2015) 125(14):2191-9. doi:10.1182/ blood-2014-08-559278

27. Kukreja K, Gruppo R, Chima R, Ristagno R, Racadio J. Developing a pediatric endovascular thrombolysis program: a single-center experience. Pediatr Radiol (2013) 43(8):1024-9. doi:10.1007/s00247-013-2634-0

28. Manco-Johnson MJ, Nuss R, Hays T, Krupski W, Drose J, Manco-Johnson ML. Combined thrombolytic and anticoagulant therapy for venous thrombosis in children. J Pediatr (2000) 136(4):446-53. doi:10.1016/S0022-3476(00)90006-4

29. Wang M, Hays T, Balasa V, Bagatell R, Gruppo R, Grabowski EF, et al. Low-dose tissue plasminogen activator thrombolysis in children. JPediatr Hematol Oncol (2003) 25(5):379-86. doi:10.1097/00043426-200305000-00006

30. Leary SE, Harrod VL, de Alarcon PA, Reiss UM. Low-dose systemic thrombolytic therapy for deep vein thrombosis in pediatric patients. J Pediatr Hematol Oncol (2010) 32(2):97-102. doi:10.1097/MPH.0b013e3181cc826e

31. Dandoy CE, Kukreja KU, Gruppo RA, Patel MN, Tarango C. Outcomes in children with deep vein thrombosis managed with percutaneous endovascular thrombolysis. Pediatr Radiol (2014) 45(5):719-26. doi:10.1007/ s00247-014-3209-4

32. Knöfler R, Dinger J, Kabus M, Müller D, Lauterbach I, Rupprecht E, et al. Thrombolytic therapy in children - clinical experiences with recombinant tissue-plasminogen activator. Semin Thromb Hemost (2001) 27(2):169-74. doi:10.1055/s-2001-14077

33. Goldenberg NA, Branchford B, Wang M, Ray C Jr, Durham JD, MancoJohnson MJ. Percutaneous mechanical and pharmacomechanical thrombolysis for occlusive deep vein thrombosis of the proximal limb in adolescent subjects: findings from an institution-based prospective inception cohort study of pediatric venous thromboembolism. J Vasc Interv Radiol (2011) 22(2):121-32. doi:10.1016/j.jvir.2010.10.013

34. Zaghlool D, Franz R, Jenkins J. EkoSonic thrombolysis as a therapeutic adjunct in venous occlusive disease. Int J Angiol (2016) 25(04):203-9. doi:10.1055/s-0036-1580698

35. Strijkers RHW, de Wolf MAF, Arnoldussen CWKP, Timbergen MJM, de Graaf R, Cate-Hoek Ten AJ, et al. Venous in-stent thrombosis treated by ultrasound accelerated catheter directed thrombolysis. Eur J Vasc Endovasc Surg (2015) 49(4):440-7. doi:10.1016/j.ejvs.2015.01.006

36. Manco-Johnson MJ, Grabowski EF, Hellgreen M, Kemahli AS, Massicotte MP, Muntean W, et al. Recommendations for tPA thrombolysis in children. On behalf of the Scientific Subcommittee on Perinatal and Pediatric Thrombosis of the Scientific and Standardization Committee of the International Society of Thrombosis and Haemostasis. Thromb Haemost (2002) 88(1):157-8.

37. Kuo I, Smith J, Abou-Zamzam AM. A multimodal therapeutic approach to phlegmasia cerulea dolens in a pediatric patient. J Vasc Surg (2011) 53(1):212-5. doi:10.1016/j.jvs.2010.07.067

38. Goldenberg NA, Durham JD, Knapp-Clevenger R, Manco-Johnson MJ. A thrombolytic regimen for high-risk deep venous thrombosis may substantially reduce the risk of postthrombotic syndrome in children. Blood (2007) 110(1):45-53. doi:10.1182/blood-2006-12-061234

39. Darbari DS, Desai D, Arnaldez F, Desai K, Kallen J, Strouse J, et al. Safety and efficacy of catheter directed thrombolysis in children with deep venous thrombosis. Br J Haematol (2012) 159(3):376-8. doi:10.1111/bjh.12025

40. Robertson L, McBride O, Burdess A. Pharmacomechanical thrombectomy for iliofemoral deep vein thrombosis. Cochrane Database Syst Rev (2016) 11:CD011536. doi:10.1002/14651858.CD011536.pub2

41. Bozkaya H, Cinar C, Ertugay S, Korkmaz M, Guneyli S, Posacioglu H, et al. Endovascular treatment of iliac vein compression (May-Thurner) syndrome: angioplasty and stenting with or without manual aspiration thrombectomy and catheter-directed thrombolysis. Ann Vasc Dis (2015) 8(1):21-8. doi:10.3400/ avd.oa.14-00110

42. Birn J, Vedantham S. May-Thurner syndrome and other obstructive iliac vein lesions: meaning, myth, and mystery. Vasc Med (2015) 20(1):74-83. doi:10.1177/1358863X14560429 
43. Melby SJ, Vedantham S, Narra VR, Paletta GA Jr, Khoo-Summers L, Driskill $\mathrm{M}$, et al. Comprehensive surgical management of the competitive athlete with effort thrombosis of the subclavian vein (Paget-Schroetter syndrome). J Vasc Surg (2008) 47(4):809.e-20.e. doi:10.1016/j.jvs.2007.10.057

44. Bjarnason H, Kruse JR, Asinger DA, Nazarian GK, Dietz CA Jr, Caldwell MD, et al. Iliofemoral deep venous thrombosis: safety and efficacy outcome during 5 years of catheter-directed thrombolytic therapy. J Vasc Interv Radiol (1997) 8(3):405-18. doi:10.1016/S1051-0443(97)70581-5

45. Bavare AC, Naik SX, Lin PH, Poi MJ, Yee DL, Bronicki RA, et al. Catheterdirected thrombolysis for severe pulmonary embolism in pediatric patients. Ann Vasc Surg (2014) 28(7):.e1-1794. doi:10.1016/j.avsg.2014.03.016

46. Mortimer AM, Bradley MD, O’Leary S, Renowden SA. Endovascular treatment of children with cerebral venous sinus thrombosis: a case series. Pediatr Neurol (2013) 49(5):305-12. doi:10.1016/j.pediatrneurol.2013.07.008

47. Albisetti M. Thrombolytic therapy in children. Thromb Res (2006) 118(1): 95-105. doi:10.1016/j.thromres.2004.12.018

48. Gupta AA, Leaker M, Andrew M, Massicotte P, Liu L, Benson LN, et al. Safety and outcomes of thrombolysis with tissue plasminogen activator for treatment of intravascular thrombosis in children. J Pediatr (2001) 139(5):682-8. doi:10.1067/mpd.2001.118428

49. Newall F, Browne M, Savoia H, Campbell J, Barnes C, Monagle P. Assessing the outcome of systemic tissue plasminogen activator for the management of venous and arterial thrombosis in pediatrics. J Pediatr Hematol Oncol (2007) 29(4):269-73. doi:10.1097/MPH.0b013e318047b78b

50. Mitchell LG, Goldenberg NA, Male C, Kenet G, Monagle P, Nowak-Gottl U, et al. Definition of clinical efficacy and safety outcomes for clinical trials in deep venous thrombosis and pulmonary embolism in children. J Thromb Haemost (2011) 9(9):1856-8. doi:10.1111/j.1538-7836.2011.04433.x

51. Vedantham S, Piazza G, Sista AK, Goldenberg NA. Guidance for the use of thrombolytic therapy for the treatment of venous thromboembolism. J Thromb Thrombolysis (2016) 41(1):68-80. doi:10.1007/s11239015-1318-z

52. Dukkipati R, Yang EH, Adler S, Vintch J. Acute kidney injury caused by intravascular hemolysis after mechanical thrombectomy. Nat Clin Pract Nephrol (2009) 5(2):112-6. doi:10.1038/ncpneph1019
53. Kukreja KU, Gollamudi J, Patel MN, Johnson ND, Racadio JM. Inferior vena cava filters in children: our experience and suggested guidelines. J Pediatr Hematol Oncol (2011) 33(5):334-8. doi:10.1097/MPH.0b013e3182191dac

54. Mewissen MW, Seabrook GR, Meissner MH, Cynamon J, Labropoulos N, Haughton SH. Catheter-directed thrombolysis for lower extremity deep venous thrombosis: report of a national multicenter registry. Radiology (1999) 211(1):39-49. doi:10.1148/radiology.211.1.r99ap4739

55. Gaballah M, Shi J, Kukreja K, Raffini L, Tarango C, Keller M, et al. Endovascular thrombolysis in the management of iliofemoral thrombosis in children: a multi-institutional experience. J Vasc Interv Radiol (2016) 27(4):524-30. doi:10.1016/j.jvir.2015.12.753

56. Lee S, Ananth P, Boyd T, Esrick E, Kim HB. Successful surgical thrombectomy for neonatal IVC and bilateral renal vein thrombosis. J Pediatric Surg Case Rep (2014) 2(4):176-9. doi:10.1016/j.epsc.2014.03.009

57. Dechant MJ, Siepe M, Stiller B, Grohmann J. Surgical thrombectomy of two left ventricular thrombi in a child with acute myocarditis. Pediatrics (2013) 131(4):e1303-7. doi:10.1542/peds.2012-1185

58. Loh A, Bishop M, Krasin M, Davidoff AM, Langham MR Jr. Long-term physiologic and oncologic outcomes of inferior vena cava thrombosis in pediatric malignant abdominal tumors. J Pediatr Surg (2015) 50(4):550-5. doi:10.1016/j.jpedsurg.2014.11.044

59. Watson L, Broderick C, Armon MP. Thrombolysis for acute deep vein thrombosis. Cochrane Database Syst Rev (2016) 11:CD002783. doi:10.1002/14651858. CD002783.pub4

Conflict of Interest Statement: The authors declare that the review was conducted in the absence of any commercial or financial relationships that could be construed as a potential conflict of interest.

Copyright (c) 2017 Tarango and Manco-Johnson. This is an open-access article distributed under the terms of the Creative Commons Attribution License (CC BY). The use, distribution or reproduction in other forums is permitted, provided the original author(s) or licensor are credited and that the original publication in this journal is cited, in accordance with accepted academic practice. No use, distribution or reproduction is permitted which does not comply with these terms. 